\title{
Assays for laboratory confirmation of novel human coronavirus (hCoV-EMC) infections
}

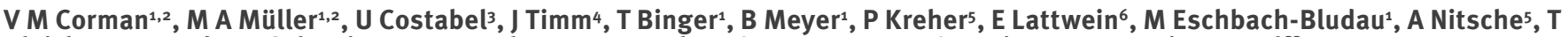
Bleicker $^{1}$, O Landt L $^{7}$ B Schweiger ${ }^{5}$, J F Drexler ${ }^{1}$, A D Osterhaus ${ }^{8}$, B L Haagmans ${ }^{8}$, U Dittmer ${ }^{4}$, F Bonin ${ }^{3}$, T Wolff5,

C Drosten (drosten@virology-bonn.de) ${ }^{1}$

1. Institute of Virology, University of Bonn Medical Centre, Bonn, Germany

2. These authors contributed equally to this work

3. Ruhrlandklinik, University of Duisburg-Essen, Essen, Germany

4. Institute of Virology, University of Duisburg-Essen, Essen, Germany

5. Robert Koch Institute, Berlin, Germany

6. Euroimmun AG, Lübeck, Germany

7. TibMolbiol, Berlin, Germany

8. Virosciences Laboratory, Erasmus MC, Rotterdam, the Netherlands

Citation style for this article:

Corman VM, Müller MA, Costabel U, Timm J, Binger T, Meyer B, Kreher P, Lattwein E, Eschbach-Bludau M, Nitsche A, Bleicker T, Landt O, Schweiger B, Drexler JF, Osterhaus AD, Haagmans BL, Dittmer U, Bonin F, Wolff T, Drosten C. Assays for laboratory confirmation of novel human coronavirus (hCoV-EMC) infections. Euro Surveill. 2012;17(49):pii=20334. Available online: http://www.eurosurveillance.org/ViewArticle.aspx?Articleld=20334

We present a rigorously validated and highly sensitive confirmatory real-time RT-PCR assay ( $1 A$ assay) that can be used in combination with the previously reported $u p E$ assay. Two additional RT-PCR assays for sequencing are described, targeting the $R d R p$ gene (RdRpSeq assay) and $N$ gene (NSeq assay), where an insertion/deletion polymorphism might exist among different hCoV-EMC strains. Finally, a simplified and biologically safe protocol for detection of antibody response by immunofluorescence microscopy was developed using convalescent patient serum.

\section{Introduction}

A novel human coronavirus, hCoV-EMC, has recently emerged in the Middle East region [1-3]. The virus has caused severe acute respiratory infection (SARI) in at least nine patients to date. Latest reports from the World Health Organization (WHO) suggest that infections have occurred since April 2012, as hCoV-EMC was found retrospectively in two patients from a group of 11 epidemiologically linked cases of SARI in Jordan, eight of whom were healthcare workers [4].

We have recently presented methods for the rapid detection of hCoV-EMC by real-time reverse transcription polymerase chain reaction (RT-PCR) [2]. One of these protocols, the $u p E$ gene assay, has been used as a first-line diagnostic assay for all human cases to date. More than 100 laboratories worldwide have since been equipped with positive-control material necessary to conduct the $u p E$ assay. We also presented a confirmatory RT-PCR assay targeting the open reading frame (ORF) $1 b$ gene, with slightly lower sensitivity than the $U P E$ assay.

In view of the growing knowledge of the epidemiology of hCoV-EMC infections, WHO is continuously updating its guidelines for laboratory testing. During an expert consultation on 28 November 2012, it was concluded that first-line screening should involve the $u p E$ assay [2]. Confirmatory testing can involve any appropriately validated RT-PCR assay for alternative targets within the viral genome, followed by sequencing of at least a portion of one viral gene that can then be compared with hCoV-EMC sequences deposited in GenBank.

Recent investigations into a cluster of cases in Saudi Arabia have revealed the possibility that the virus may not be detected by RT-PCR in all patients with symptoms and proven epidemiological linkage [5]. From our previous experience during the severe acute respiratory syndrome (SARS) epidemic in 2003, such issues were predicted to occur when testing by RT-PCR alone [2]. In SARS patients, in particular those seen more than 10 days after symptom onset, serological testing by immunofluorescence assay (IFA) has been successfully used to complement RT-PCR findings $[6,7]$.

On 22 November 2012, German health authorities were notified of a patient who had been treated for SARI in a hospital in Essen, Germany [5]. On the basis of clinical samples from this case, we present here a set of validated assays for the confirmation of cases of hCoV-EMC infection, including a confirmatory real-time RT-PCR assay in the ORF1a gene, two sequencing amplicons in the RNA-dependent RNA polymerase $(R d R p)$ and nucleocapsid $(N)$ protein genes, as well as a straightforward methodology for biologically safe immunofluorescence testing. 


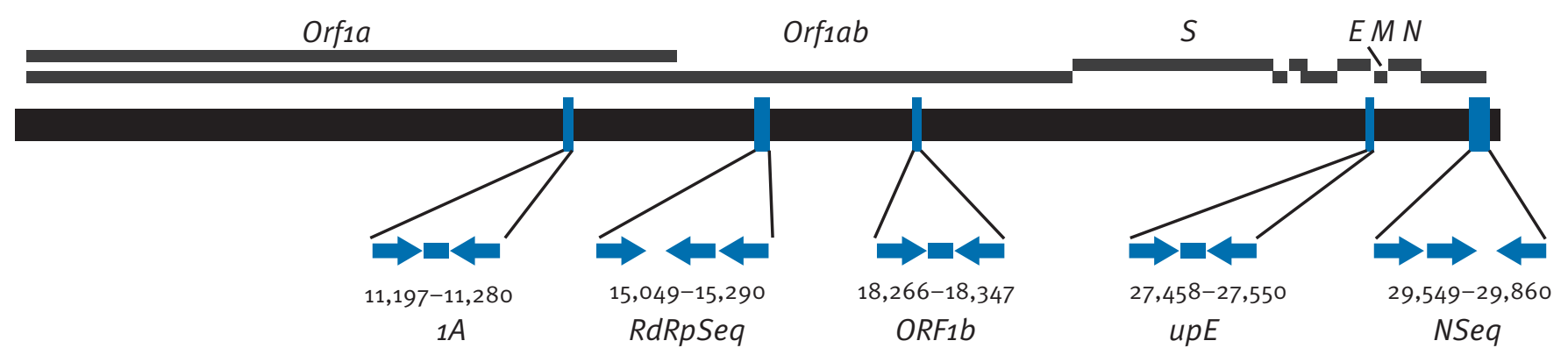

$N$ : nucleocapsid; Orf: open reading frame; RdRp: RNA-dependent RNA polymerase; RT-PCR: reverse transcription-polymerase chain reaction.

The figure shows the relative positions of amplicon targets presented in this study, as well as in [2]. Primers are represented by arrows, probes as blue bars. Numbers below amplicon symbols are genome positions according to the hCoV-EMC/2012 prototype genome presented in [1].

The $1 A$ assay is the confirmatory real-time RT-PCR test presented in this study (target in the ORF1a gene). The RdRpSeq assay is a hemi-nested sequencing amplicon presented in this study (target in the RdRp gene). The ORF1b assay is a confirmatory real-time RT-PCR presented in [2]. The upE assay is a real-time RT-PCR assay recommended for first-line screening as presented in [2] (target upstrem of $E$ gene). The NSeq assay is a hemi-nested sequencing amplicon presented in this study (target in $N$ gene).

\section{Methods}

RT-PCR assays for the screening and confirmation of infections with hCoV-EMC Figure 1 provides a summary of the target regions on the viral genome for screening, confirmation and sequence determination. Documentation on sources of materials used is provided in the Acknowledgements section.

\section{RNA preparation}

The procedures for RNA preparation have been described previously [2].

\section{Confirmatory real-time RT-PCR}

assay in ORF $1 a$ ( $1 A$ assay)

A $25 \mu \mathrm{l}$ reaction was set up containing $5 \mu \mathrm{l}$ of RNA, $12.5 \mu \mathrm{l}$ of $2 \mathrm{X}$ reaction buffer from the Superscript III one step RT-PCR system with Platinum Taq Polymerase (Invitrogen; containing $0.4 \mathrm{mM}$ of each dNTP and 3.2

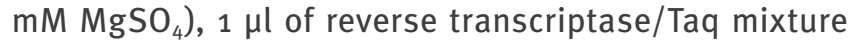
from the kit, $0.4 \mu \mathrm{l}$ of a $50 \mathrm{mM} \mathrm{MgCl}$ solution (Invitrogen - not provided with the kit), $1 \mu \mathrm{g}$ of non-acetylated bovine serum albumin (Sigma), $400 \mathrm{nM}$ of primers EMC-Orf $1 a$-Fwd (CCACTACTCCCATTTCGTCAG) and EMCOrfia-Rev (CAGTATGTGTAGTGCGCATATAAGCA), as well as $200 \mathrm{nM}$ of probe EMCOrf1a-Prb (6-carboxyfluorescein (FAM)-TTGCAAATTGGCTTGCCCCCACT -6-carboxy$\mathrm{N}, \mathrm{N}, \mathrm{N}, \mathrm{N}^{-}$-tetramethylrhodamine (TAMRA)). Thermal cycling was performed at $55^{\circ} \mathrm{C}$ for $20 \mathrm{~min}$ for the RT, followed by $95^{\circ} \mathrm{C}$ for 3 min and then 45 cycles of $95^{\circ} \mathrm{C}$ for $15 \mathrm{~s}, 58^{\circ} \mathrm{C}$ for $30 \mathrm{~s}$.
RT-PCR for generating amplicons for sequencing the $R d R p$ gene target ( $R d R p S e q$ assay)

For the first round, a $25 \mu \mathrm{l}$ reaction was set up containing $5 \mu \mathrm{l}$ of RNA, $12.5 \mu \mathrm{l}$ of $2 \mathrm{X}$ reaction buffer from the Superscript III one step RT-PCR system with Platinum Taq Polymerase (Invitrogen; containing $0.4 \mathrm{mM}$ of each dNTP and $3.2 \mathrm{mM} \mathrm{MgSO}_{4}$ ), $1 \mu$ l of reverse transcriptase/ Taq mixture from the kit, $0.4 \mu \mathrm{l}$ of a $50 \mathrm{mM} \mathrm{MgSO}$ solution (Invitrogen - not provided with the kit), $1 \mu \mathrm{g}$ of non-acetylated bovine serum albumin (Sigma), 400 $n M$ of each primer RdRpSeq-Fwd (TGC TAT WAG TGC TAA GAA TAG RGC; $R=A / G, W=A / T$ ) and RdRpSeq-Rev (GCA TWG CNC WGT CAC ACT TAG G; W=A/T, N=A/C/ $\mathrm{T} / \mathrm{G}$ ). Thermal cycling was performed at $50{ }^{\circ} \mathrm{C}$ for 20 min, followed by $95^{\circ} \mathrm{C}$ for 3 min and then 45 cycles of $95^{\circ} \mathrm{C}$ for $15 \mathrm{~S}, 56^{\circ} \mathrm{C}$ for $15 \mathrm{~S}$ and $72{ }^{\circ} \mathrm{C}$ for $30 \mathrm{~s}$, with a terminal elongation step of $72{ }^{\circ} \mathrm{C}$ for $2 \mathrm{~min}$.

In cases where no amplification products were obtained with the RT-PCR assay, a $50 \mu \mathrm{l}$ second-round reaction was set up containing $1 \mu \mathrm{l}$ of reaction mixture from the first round, $5 \mu \mathrm{l}$ of $10 \mathrm{X}$ reaction buffer provided with the Platinum Taq Polymerase Kit (Invitrogen), $2 \mu$ l of a $50 \mathrm{mM} \mathrm{MgCl}$, solution (provided with the kit), $200 \mu \mathrm{M}$ of each dNTP, $400 \mathrm{nM}$ concentrations of each second round primer RdRpSeq-Fwd (the same as in the first round) and RdRpSeq-Rnest (CAC TTA GGR TAR TCC CAW CCC A) and $0.2 \mu \mathrm{l}$ of Platinum Taq from the kit. Thermal cycling was performed at $95^{\circ} \mathrm{C}$ for 3 min and 45 cycles of $95^{\circ} \mathrm{C}$ for $15 \mathrm{~S}, 56^{\circ} \mathrm{C}$ for $15 \mathrm{~S}$ and $72{ }^{\circ} \mathrm{C}$ for $30 \mathrm{~s}$, followed by a 2 min extension step at $72{ }^{\circ} \mathrm{C}$. 
RT-PCR for sequencing in the $N$ gene

(NSeq assay)

The assay employed the same conditions as the RdRpSeq assay, except that the primer sequences were NSeq-Fwd (CCT TCG GTA CAG TGG AGC CA) and NSeqRev (GAT GGG GTT GCC AAA CAC AAA C) for the first round and NSeq-Fnest (TGA CCC AAA GAA TCC CAA CTA C) and NSeq-Rev (the same as in the first round) for the second round. The second round was only done if no product was visible by agarose gel electrophoresis after the first round.

\section{Virus quantification by real-time RT-}

\section{PCR using in-vitro transcribed RNA}

In-vitro transcribed RNA was prepared as described previously [2]. Serial 10-fold dilutions of this RNA were amplified in parallel with samples in a Roche LightCycler 48oll after entering the known RNA concentrations of standards in the quantification module of the operation software. Virus concentrations in terms of genome copies per $\mathrm{ml}$ of original sample were extrapolated using a conversion factor of 85.7 , as explained previously [2].

\section{Virus growth, infection and titration}

Virus stocks of the clinical isolate $\mathrm{hCoV}-\mathrm{EMC} / 2012$ (kindly provided by Ron Fouchier [1]) were grown on African green monkey kidney (Vero B4) cells. Cells were infected at a multiplicity of infection (MOI) of 0.01 and supernatants were harvested two days post infection. Titres were determined by plaque assay on Vero B4 cells as described previously [8].

$\mathrm{hCoV}$-EMC antibody detection assays

Two IFAs have been developed.

\section{(i) Conventional IFA}

Vero cells were seeded onto glass coverslips in 24-well plates, grown to subconfluence, and infected at an $\mathrm{MOI}$ of 0.5 . After 24 hours, cell monolayers were fixed with acetone [9].

\section{(ii) Rapid, biologically safe IFA}

Vero B4 cells in flasks were infected at an $\mathrm{MOI}$ of 0.01 and harvested two days post infection. Infected cells were mixed with non-infected Vero B4 cells (ratio 1:1) and spotted on glass slides by dispensing and immediately aspirating the cell suspension. The concentration of the cell suspension was $10 e 7$ cells per $\mathrm{ml}$ in medium. The time between dispensing and back-aspiration was 2 seconds. About 6 wells could be loaded with the content of one $50 \mu$ l pipette tip. It was important for the success of cell spotting that the IFA slides used for the procedure should have undergone aggressive cleaning and autoclaving before use. After drying, the slides were fixed and virus inactivated with $4 \%$ paraformaldehyde for 30 minutes. Slides were immersed into ice-cold acetone/methanol (ratio 1:1) to permeabilise the cells. In the assay, patient sera ( $25 \mu \mathrm{l}$ per dilution) were subjected to serial dilution in sample buffer (Euroimmun AG, Lübeck, Germany) starting at 1:40 and applied at
$25 \mu \mathrm{l}$ per well. As a positive control, a macaque-anti$\mathrm{hCoV}$-EMC (day 14 post infection), provided by author B. H. was used in a 1:20 dilution. Slides were incubated at $37^{\circ} \mathrm{C}$ for 1 hour (rapid slides) or at room temperature for 30 minutes (conventional coverslips) and washed three times with phosphate-buffered saline (PBS)Tween (0.1\%) for 5 minutes. The secondary antibody was a goat-anti human Cyz-labelled immunoglobulin G conjugate. After incubation at $37^{\circ} \mathrm{C}$ (spotted slides) or room temperature (conventional coverslips) for $30 \mathrm{~min}$ utes, they were washed three times with PBS-Tween for 5 minutes, rinsed with water and mounted with DAPI ProLong mounting medium (Life Technologies).

\section{Recombinant assays for confirmatory \\ IFA and western blot analysis}

The hCoV-EMC/2012 spike $(S)$ and $N$ genes were amplified from CDNA. For PCR amplification of FLAG-tagged $N$ and $S$ and subsequent cloning into a $\mathrm{pCG}_{1}$ vector (kindly provided by Georg Herrler, TIHO, Hannover), the following primers were used: $2 \mathrm{C}-\mathrm{nhCoV}$-SflagN-BamHI-F (TACGGATCCGCCACCATGGATTACAAGGATGACGATGACAA GGGAGGCATACACTCAGTGTTTCTACTGATGT), 2c-nhCoV-S-Sall-R (AGCGTCGACTTAGTGAACATGAAC CTTATGCGG), 2C-nhCoV-NflagN-BamHI-F (TACGGATCCGCCACCATGGATTACAAGGATGACGATG ACAAGGGAGGCGCATCCCCTGCTGCACCTCGT)

and $2 \mathrm{C}-\mathrm{nhCoV}-\mathrm{N}-\mathrm{Xbal}-\mathrm{R}$

(AGCTCTAGACTAATCAGTGTTAACATCAATCATTG).

For IFA, Vero $\mathrm{B}_{4}$ cells were transfected in suspension using $0.5 \mu \mathrm{g}$ of plasmid DNA and the FuGENE HD protocol (Roche, Basel, Switzerland). Transfected cells were seeded into a 24-well plate containing glass coverslips. After 24 hours, cells were fixed with $4 \%$ paraformaldehyde, washed twice with PBS-Tween and permeabilised with PBS containing $0.1 \%$ Triton X-100. For western blot analysis of recombinant spike and nucleocapsid proteins, transfections were performed similarly but in six-well plates with HEK-293T cells using $2 \mu \mathrm{g}$ of plasmid DNA. After 24 hours post-transfection, cells were washed three times with ice-cold PBS and harvested for western blot analysis. Cell lysis was performed with RIPA lysis buffer containing Protease Inhibitor Cocktail III (Calbiochem, San Diego, United States), 5mM DTT and nuclease $(25 \mathrm{U} / \mathrm{ml})$. Lysates from untransfected HEK-293T cells were used as controls. Patient serum was serially diluted 1:100 to $1: 8,000$ in PBS-Tween with $1 \%$ milk powder. Blot strips were incubated for 1.5 hours at room temperature. The secondary antibody, a horseradish peroxidase-conjugated goat-anti human immunoglobulin, was applied $(1: 20,000$ in PBSTween with $1 \%$ milk powder). Detection was performed by using SuperSignal West Pico Chemiluminescence Substrate (Pierce Biotechnology).

\section{Results}

$1 A$ assay

The $1 A$ RT-PCR assay is directed to the Orfia gene: this was optimised for sensitivity by testing several 


\section{FIGURE 2}

Technical limit of detection for the $1 A$ assay, novel human coronavirus (hCoV-EMC)

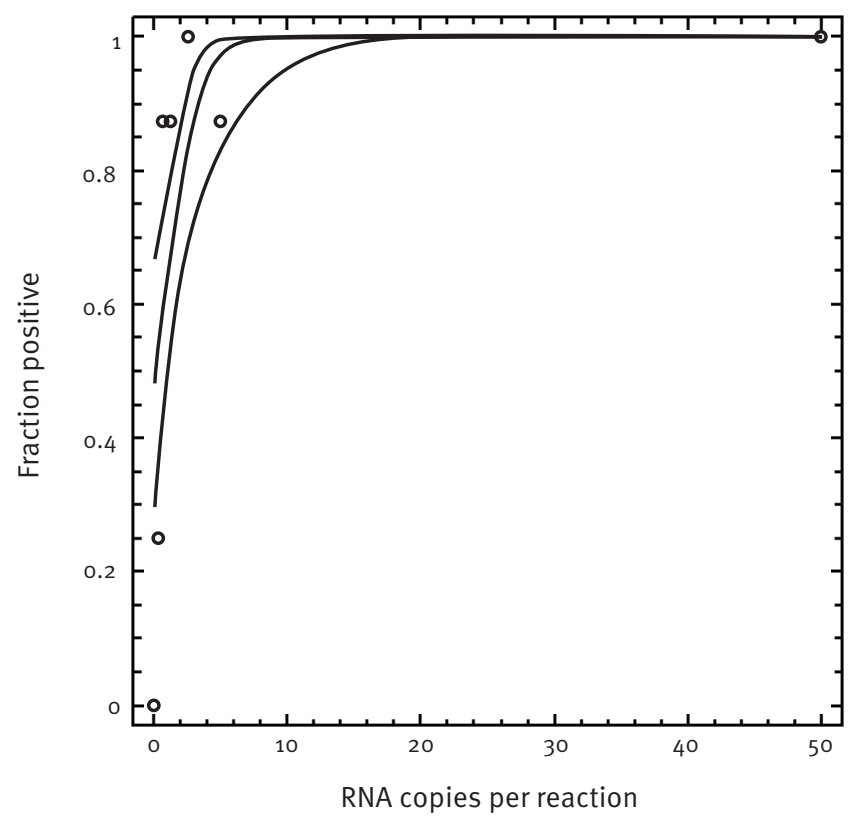

The $1 A$ assay is the confirmatory real-time RT-PCR test presented in this study (target in ORF1a).

Probit regression analysis using results from parallel runs of the $1 A$ assay containing very low concentrations of in-vitro transcribed hCoV-EMC RNA (between 50 and 0.3 average copies per reaction, 16 parallel determinations per datum point). different candidate primers. The assay was compared with the $u p E$ assay by testing dilution series of the cell culture supernatant containing hCoV-EMC. There was complete concordance of the endpoints of the two assays. A total of 40 reactions using water instead of RNA were performed, in order to exclude any artificial signals due to irregular primer-/probe hybridisations. In-vitro transcribed RNA was generated for the peri-amplicon region of the $1 A$ assay and used for parallel end-point dilution testing and probit regression analysis. The target concentration at which $>95 \%$ of $1 A$ assays can be expected to yield positive results was 4.1 RNA copies per reaction tube, i.e. a sensitivity equivalent to that of the upE assay ([2] and Figure 2). To exclude the possibility of false-positive results, human coronaviruses $229 \mathrm{E}, \mathrm{NL63}, \mathrm{OC} 43$, as well as SARS-CoV were tested in form of cell-culture supernatants in both assays (Table). A total of 42 clinical samples known to contain other respiratory viruses were tested as well, eight of which contained human coronaviruses including the unculturable hCoV-HKU1: all samples yielded negative results (Table).

For a final comparison of sensitivity, the $u p E, O R F_{1} b$, and $1 A$ assays were applied in parallel reactions to test a bronchoalveolar lavage sample from the patient treated in Essen, Germany. This sample had a very low RNA concentration of 360 copies per $\mathrm{ml}$ as determined with the $u p E$ assay using in-vitro transcribed RNA as the quantification standard [2]. The $u p E$ and $1 A$ assays consistently detected RNA in this sample in repeated tests. The concentration determined by the $1 A$ assay was between 66.5 and 100 copies per $\mathrm{ml}$, reflecting

\section{TABLE}

Summary of experiments to determine sensitivity and cross-reactivity, novel human coronavirus (hCoV-EMC)

\begin{tabular}{|c|c|}
\hline Experiment & ORF1b assay \\
\hline Technical limit of detection ${ }^{a}$ & $\begin{array}{l}\text { 4.1 RNA copies/reaction } \\
(95 \% \mathrm{Cl}: 2.8-9.5)\end{array}$ \\
\hline Cross-reactivity with hCoV-229E & $\begin{array}{l}\text { No reactivity with virus stock containing } 10^{5} \mathrm{PFU} / \mathrm{ml} \\
\left(3 \times 10^{9} \text { RNA copies } / \mathrm{ml}\right)\end{array}$ \\
\hline Cross-reactivity with hCoV-NL63 & $\begin{array}{l}\text { No reactivity with virus stock containing } 10^{6} \mathrm{PFU} / \mathrm{ml} \\
\left(4 \times 10^{9} \mathrm{RNA} \text { copies } / \mathrm{ml}\right)\end{array}$ \\
\hline Cross-reactivity with SARS-CoV & $\begin{array}{l}\text { No reactivity with virus stock containing } 3 \times 10^{6} \mathrm{PFU} / \mathrm{ml} \\
\left(5 \times 10^{10} \text { RNA copies } / \mathrm{ml}\right)\end{array}$ \\
\hline $\begin{array}{l}\text { Cross-reactivity with clinical samples } \\
\text { containing respiratory viruses }\end{array}$ & $\begin{array}{l}\text { No reactivity with } 42 \text { samples containing the following viruses: hCoV-HKU1 }(n=3 \text { samples); hCoV-OC } 43 \\
(n=1) \text {; hCoV-NL63 }(n=3) \text {; hCoV-229E }(n=1) \text {; human rhinovirus }(n=2) \text {; enterovirus }(n=4) ; \text { human } \\
\text { parechovirus }(n=3) ; \text { human metapneumovirus }(n=4) \text {; respiratory syncytial virus }(n=3) ; \text { parainfluenza } \\
\text { virus } 1,2,3,4(n=7) ; \text { influenza A virus }(n=5) ; \text { influenza B virus }(n=2) ; \text { adenovirus }(n=4)\end{array}$ \\
\hline
\end{tabular}

PFU: plaque-forming units.

a Defined as the novel human coronavirus (hCoV-EMC) RNA concentration at which $>95 \%$ of parallel tests will return positive results. 
Comparison of RdRpSeq and NSeq assays, novel human coronavirus (hCoV-EMC)

A

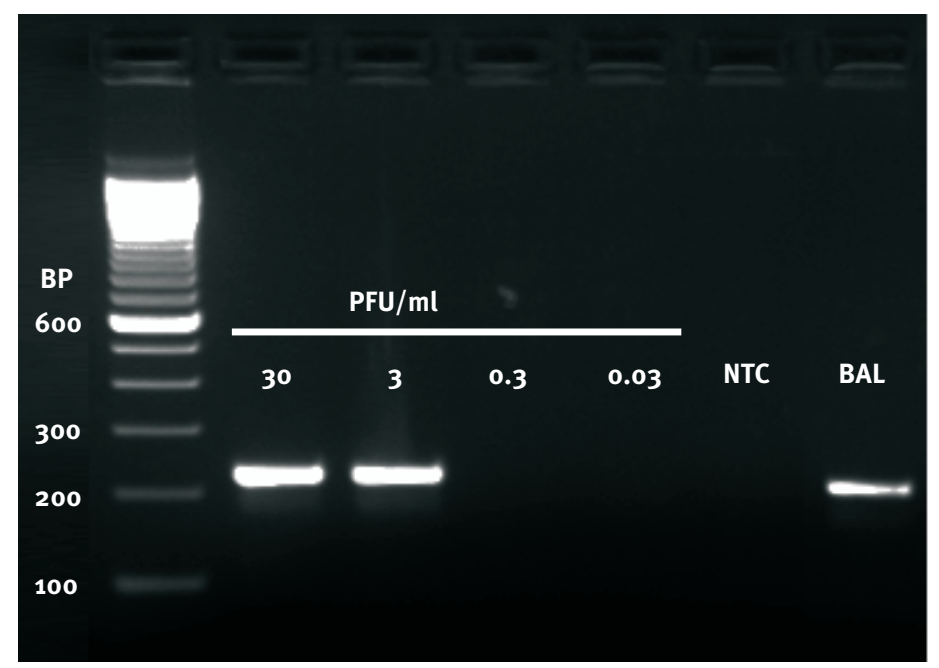

B

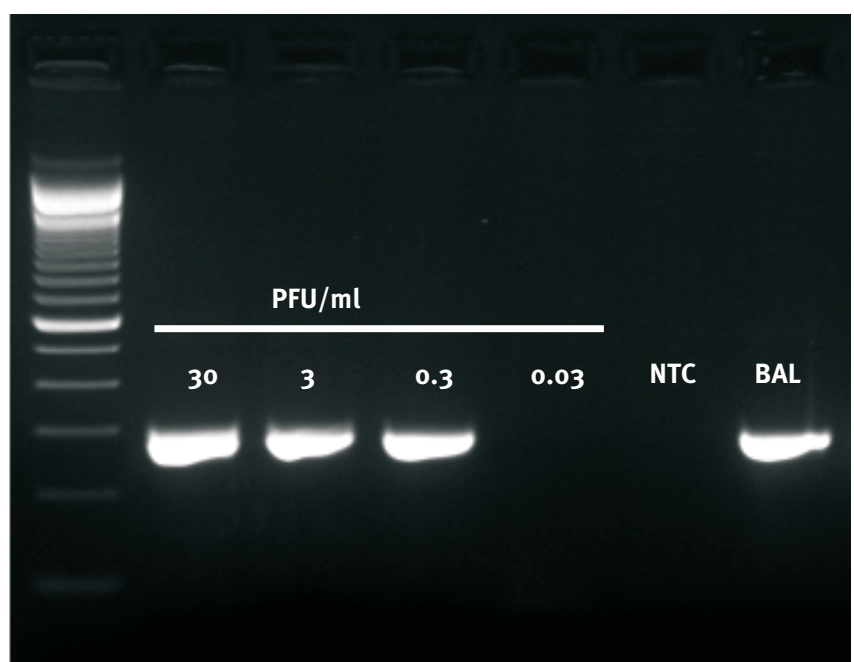

BAL: bronchoalveolar lavage; BP: base pairs; N: nucleocapsid; NTC: No template control; RdRp: RNA-dependent RNA polymerase; PFU: plaqueforming units; RT-PCR: reverse transcription-polymerase chain reaction.

RT-PCR amplification of sequencing fragments within the RdRp gene (panel A, RdRpSeq assay) and $N$ gene (panel B, NSeq assay). Cell culture stock solutions of hCoV-EMC were diluted to the virus concentrations specified (in PFU per ml), of which $50 \mu l$ were extracted using the Qiagen Viral RNA mini kit and tested with both assays. The NSeq assay is more sensitive than the RdRpSeq assay. Both assays detected virus in a BAL sample from the Essen, Germany, patient.

slightly lower target abundance in the non-structural gene RNA, as observed previously for SARS-CoV [10]. Critically, the ORF1b assay presented in [2] did not detect virus in this sample.

\section{$R d R p S e q$ and NSeq assays}

Two different RT-PCRs to produce amplicons for sequencing were designed. One amplicon was from the $R d R p$ gene, a common target for CoV detection and a genome region where sequences for most coronaviruses are available (RdRpSeq assay, Figure 1). The assay was designed to provide broad detection of Betacoronavirus clade $\mathrm{C}$ sequences including hCoV-EMC as well as related viruses from animal sources such as bats (unpublished observations). The other amplicon was from a highly specific fragment within the hCoVEMC $N$ gene (NSeq assay, Figure 1 ). This region was chosen because it comprised a two amino acid (6 nt) deletion in the corresponding sequence published from a patient treated in London, United Kingdom [11]. As shown in Figure 3, both amplicons were sensitive enough to detect cell culture-derived virus at very low concentrations. Both assays also yielded amplification products from the bronchoalveolar lavage sample from the Essen patient, in spite of its very low RNA concentration. Sequencing results are shown in Figure 4.

\section{hCoV-EMC antibody detection}

Finally, slides for immunofluorescence microscopy were produced following two different common protocols. While the first method, growing cells on coverslips, provides better cell morphology, the second is commonly used to circumvent the necessity to optimise infection dose and duration, and to obtain slides with no infectious virus, to meet the biosafety requirements for shipment. For the first (conventional) protocol, Vero cells were seeded on microscope coverslips and infected with virus in situ. Infection conditions had been previously optimised to ensure infection of about $30 \%$ of cells in a series of experiments. For the second option, Vero cells were infected in conventional cell culture and mixed with an equivalent quantity of uninfected cells, after which they were spotted on glass microscope slides and further inactivated with paraformaldehyde. Both types of slides were stained with serum of a cynomolgus macaque infected with hCoVEMC or with serum from the Essen patient. Figure 5, panel $A$, shows a typical coronavirus cytoplasmic fineto-medium granular fluorescence with pronounced perinuclear accumulation, sparing the nucleus on the coverslip culture. The same result was also achieved with the convalescent serum from an experimentally infected cynomolgus macaque, suggesting that this 


\section{FIGURE 4}

Sequence alignments comparing the results of RdRpSeq and Nseq sequencing assays, novel human coronavirus (hCoV-EMC) and sequence obtained from a patient from Essen, Germany

\section{A}

hCOV-EMC

London sequence

Essen sequence

$\mathrm{hCOV}-\mathrm{EMC}$

London sequence

Essen sequence

$\mathrm{hCOV}-\mathrm{EMC}$

London sequence

Essen sequence

hCOV-EMC

London sequence

Essen sequence

B

hCOV-EMC

London sequence Essen sequence

hCOV-EMC

London sequence Essen sequence

hCOV-EMC

London sequence Essen sequence

hCOV-EMC

London sequence

Essen sequence

hCOV-EMC

London sequence

Essen sequence
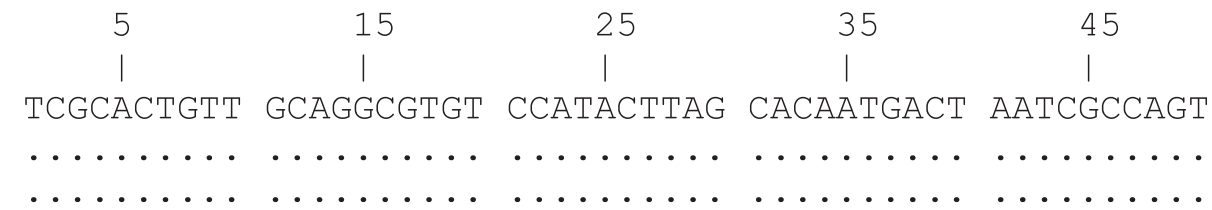

$\begin{array}{ccccc}55 & 65 & 75 & 85 & 95 \\ \mid & \mid & \mid & \mid & \mid \\ \text { ACCATCAGAA } & \text { AATGCTTAAG } & \text { TCCATGGCTG } & \text { CAACTCGTGG } & \text { AGCGACTTGC }\end{array}$
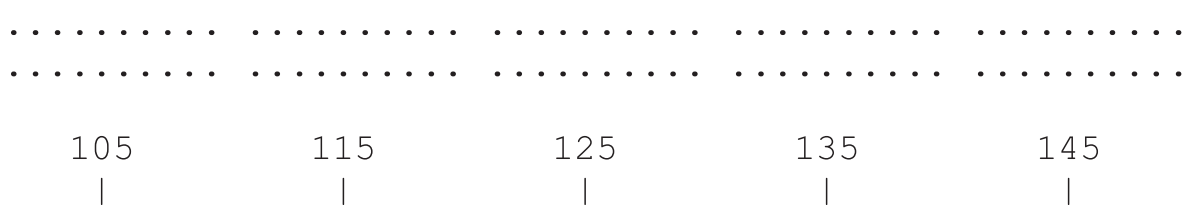

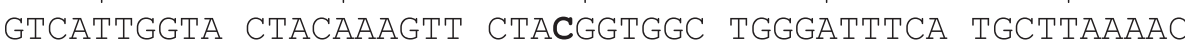

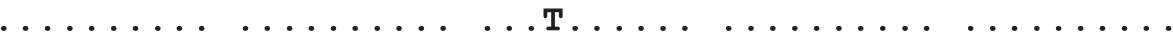

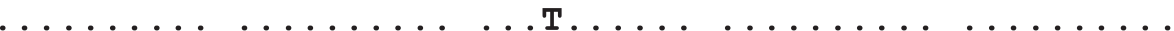

$155 \quad 165 \quad 175$

|

ATTGTACAAA GATGTTGATA ATCCGCATCT TA

$\ldots \ldots \ldots \ldots \ldots \ldots \ldots \ldots \ldots \ldots \ldots \ldots \ldots \ldots \ldots \ldots \ldots$

$\ldots \ldots \ldots \ldots \ldots \ldots \ldots \ldots \ldots$

$\begin{array}{ccccc}5 & 15 & 25 & 35 & 45 \\ 1 & 1 & \mid & \mid & \mid\end{array}$

AAtAAgtgGT TGgAgCtTCT TGAgCAAAAT ATTGATGCCT ACAAAACCTT

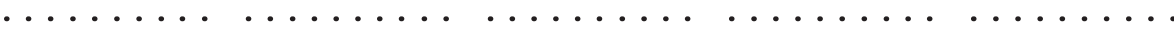

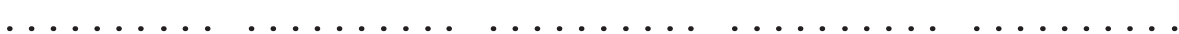

$\begin{array}{ccccc}55 & 65 & 75 & 85 & 95 \\ \text { I } & \mid & \mid & \mid & \mid\end{array}$

CCCTAAgAA GAAAAGAAC AAAAgGCACC AAAAgAAgA TCAACAgACC

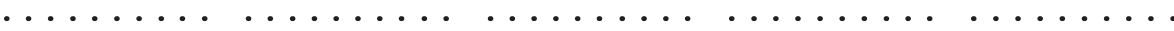

$\begin{array}{ccccc}105 & 115 & 125 & 135 & 145 \\ \mid & \mid & \mid & \mid & \text { | }\end{array}$

AAATGTCtgA ACCTCCAAAg GAgCAGCGTG TGCAAgGTAG CATCACTCAg $\ldots \ldots \ldots \ldots \ldots . \ldots \ldots \ldots \ldots$

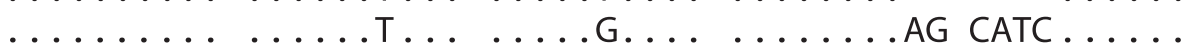

$\begin{array}{ccccc}155 & 165 & 175 & 185 & 195 \\ \text { | } & \text { I } & \text { | } & \text { | } & \text { | }\end{array}$
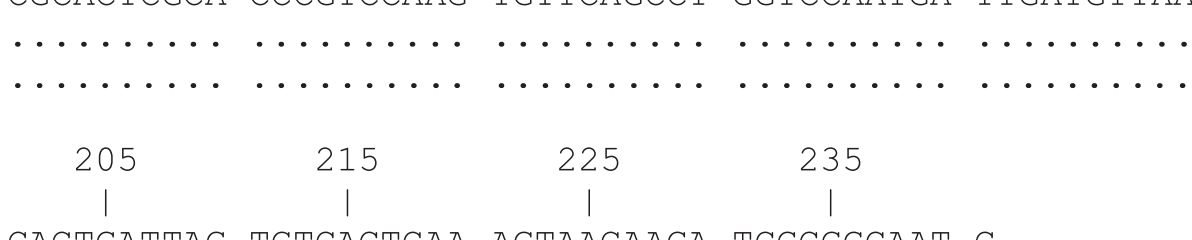

CACtgAttAg tgtCACtCAA AgtAACAAgA TCGCGgCAAT C

$\ldots \ldots \ldots \ldots \ldots \ldots \ldots \ldots \ldots \ldots \ldots \ldots \ldots \ldots \ldots \ldots \ldots \ldots$

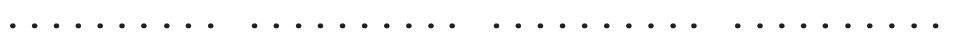

Panel A. Results from the RdRpSeq assay on the Essen patient.

Panel B. Results of the Nseq assay.

Dots represent identitical nucleotides, hyphens represent sequence gaps. 
can be used as a valid positive control in absence of available patient material. Figure 5 , panel B, shows results from two convalescent sera of the patient, taken about four weeks apart, on simplified biologically safe slides. As expected, the fluorescence pattern was less well differentiated compared with slides infected and tested in situ. However, a very clear cytoplasmic perinuclear pattern is discernible, suggesting those slides will be appropriate for diagnostic application in spite of their simpler production and safer handling.

Sera from a limited number of German blood donors were tested by this IFA assay, with no relevant falsepositive findings in a non-exposed population. However, much more validation is needed, because antibodies against betacoronaviruses are generally known to cross-react within the genus. Sera from patients with a high antibody titre against any other human coronavirus such as $\mathrm{OC}_{43}$ or HKU1 may well lead to false-positive results if tested by IFA alone. We propose to use this IFA only for patients with a very clear epidemiological linkage, ideally presenting positive results with a first-line assay such as $u p E$. Paired sera should be investigated wherever possible.

As shown in Figure 5, panel C, IFA reactivity was also demonstrated in cells overexpressing recombinant $S$ or $\mathrm{N}$ proteins. Anti-S and anti- $\mathrm{N}$ antibodies were also confirmed by western blot.

\section{Discussion}

Here we present nucleic acid-based and serological assays for the confirmation of hCoV-EMC infections. The current strategy and recommendations by WHO require reference laboratories to be involved in cases where first-line screening has provided positive results. However, with the potential occurrence of more cases of hCoV-EMC infection, the demand for confirmatory testing might grow in a way that it could overwhelm the capacity of reference laboratories. The major challenge in setting up confirmatory methodology will be the validation of tests. Technical studies can be tedious and clinical validation is hard to achieve if no patient samples are at hand. The documentation here of proven methodology is presented with those laboratories in mind that will have to provide diagnostic testing and additional reference services in the future, but cannot rely on their own validation studies.

The $1 A$ real-time RT-PCR assay provides the same sensitivity as the $u p E$ first-line assay, and should provide consistent results in case of truly positive patients. It should be mentioned that the $O R F_{1} b$ assay along with the $U p E$ assay can also serve as a highly robust confirmatory test [2]. However, patients may be seen at times when they excrete small amounts of virus, e.g. very early or very late after symptom onset [6]. Moreover, samples may be diluted due to clinical processes such as lavage, as exemplified by the case investigated here. In such instances, confirmatory assays must have the same sensitivity as the first-line
FIGURE 5

Examples of serological assays, novel human coronavirus (hCoV-EMC)

A

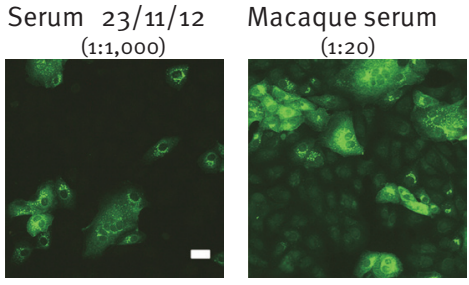

EMC/2012 infected cells
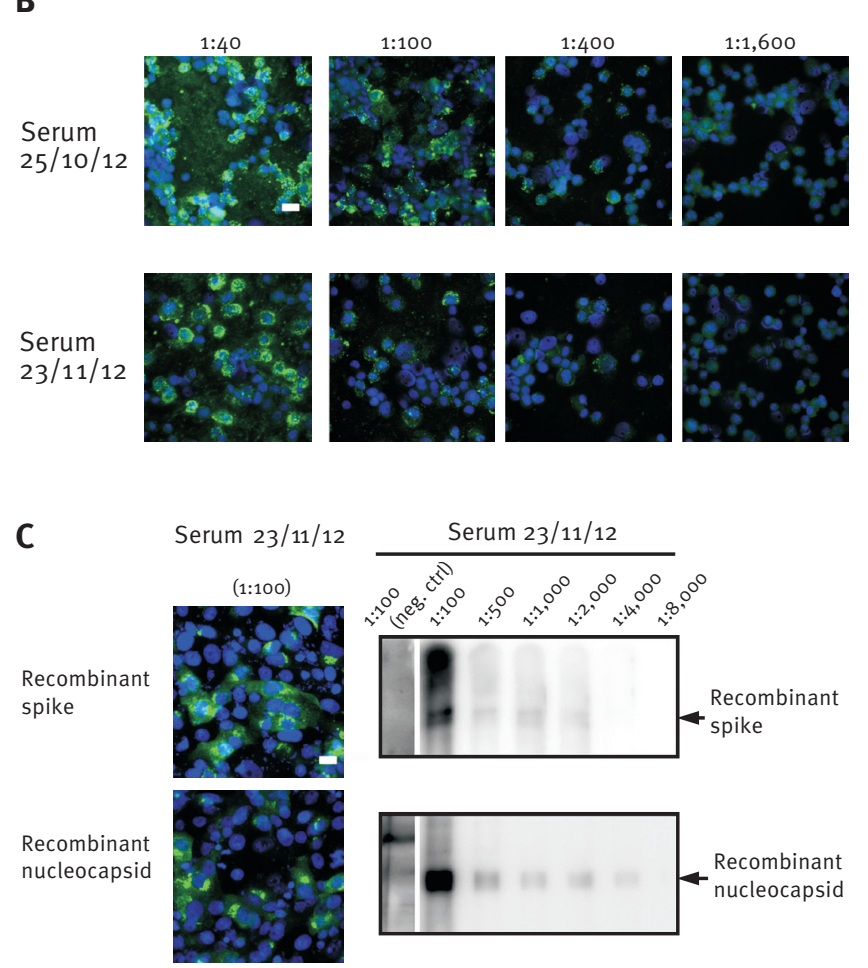

Panel A. Conventional immunofluorsecence assay (IFA) using cells grown and infected on coverslips. The patient serum from the later time point $(23 / 11 / 12)$ was tested positive in a $1: 1,000$ dilution. As control, a serum of an $\mathrm{hCoV}$-EMC/2012 infected macaque (taken 14 days post infection) was applied.

Panel B. Rapid/biologically safe immunofluorescence assay (IFA) slides. Mixed infected and non-infected Vero cells incubated with serially diluted sera from an hCoV-EMC-infected patient taken at two different time points post infection.

Panel C. IFA using Vero cells expressing recombinant spike and nucleocapsid proteins, as well as western blot against lysates from the same transfected cells.

Bars represent $20 \mu \mathrm{m}$. 
test. Such high sensitivity is achieved by the $1 A$ assay, providing an appropriate complement to the $u p E$ assay proposed previously [2].

While real-time RT-PCR products can be sequenced, the shortness of their fragments makes DNA preparation inefficient and limits the length of useful sequence information. We present here two different sequencing amplicons (RdRpSeq and NSeq assays) that will yield reasonably large fragments even from samples containing very low virus concentration. We are not proposing to preferentially use either of those two assays, as both have different properties that suggest using them in combination. The RdRpSeq assay provides sequencing results that can be compared with a large database of cognate sequences, as it is commonly used for typing coronaviruses. The amplicon overlaps to a large extent with that proposed earlier by Vijgen et al. for pancoronavirus detection, ensuring good comparability between laboratory results from different groups [12]. The primers of the RdRpSeq assay are highly conserved and will cross-react with other betacoronaviruses including hCoV-OC43 or -HKU1. Critically, this amplicon should not be used for screening if not connected with subsequent sequence analysis, as false-positive results are possible in patients infected with other human coronaviruses. In contrast, the NSeq assay provides highly sensitive and specific detection for hCoVEMC, enabling a sequence-based confirmation even for cases that present with very low virus concentration. Here it is interesting to note that a sequence presented from a patient treated in London has a deletion in the amplified fragment. We should not draw early conclusions on virus diversity from these limited data, but it will be interesting to sequence and compare the NSeq fragment from more viruses in the future, in order to determine whether lineages with and without the deletion might have formed already. The NSeq assay might be used as a tool for provisional strain classification in the future.

For the augmentation of confirmatory testing by serology, IFA, ideally in paired sera taken several days apart, proved highly robust during the SARS epidemic $[6,7]$. In contrast to EIA, IFA provides additional criteria for result interpretation via the localisation of signals within cells. False-positive reactivity can thus be circumvented. The data presented here are intended as reference for those laboratories willing to confirm cases of hCoV-EMC infection by IFA. We have shown in this single patient that antibodies were detectable by IFA at a time when the patient still presented severe disease and the virus was not yet eliminated from respiratory secretions as detectable by RT-PCR (case report to be presented elsewhere). As in many SARS patients, the antibody titre was in the medium range, below 1:1,000, even in convalescence [6]. In SARS patients, IFA seroconversions usually began to show from day 10 of symptoms onward, while virus RNA could not be detected by RT-PCR in respiratory secretions starting from day 15 onward $[6,7]$.
It is important to mention that IFA slides contain virus-infected cells which in theory could retain infectious virus. However, it has been shown in a meticulous investigation of SARS-CoV that acetone fixation of IFA slides results in the reduction of infectivity to undetectable levels. The extent of reduction of infectivity was at least $6.55 \log 10$ infectious virus doses [9] (greater reductions could not be measured by the assay applied). In the rapid and biologically safe IFA procedure we presented here, further reduction of any conceivable residues of infectivity was achieved by combining acetone fixation with paraformaldehyde treatment. This treatment was shown to confer efficient reduction on SARS-CoV [9] and is also effective against other enveloped RNA viruses [13]. No residual infectivity should exist in the rapid and biologically safe IFA slides described here.

We have also shown that there is good correlation between IFA results and western blot against the two major structural proteins, S and N. Western blotting might therefore be an option as a confirmatory diagnostic for serology. However, in absence of data from a considerably larger number of patients, care must be taken in interpreting the results from western blot alone, as SARS patients were found to vary in their immune responses against single proteins in western blot $[14,15]$. Not only western blot but also neutralisation tests should be evaluated for their capacity to afford a highly specific confirmation of serological results [7]. This is of particular importance because it is unknown to what extent hCoV-EMC antibodies crossreact with those against common human coronaviruses such as $\mathrm{OC}_{43}$ and HKU1. In the present study, we have not investigated cross-reactivity in a larger group of patients, as this requires meticulous counter-testing and selection of samples with high titres against other human coronaviruses, as well as confirmation by additional methods such as differential virus neutralisation tests. The serological data presented here should be regarded as suggestions for confirmatory testing of epidemiologically linked individuals, or of cases under investigation due to positive results in first-line tests.

\section{Acknowledgments}

The development and provision of these assays was done by a European research project on emerging diseases detection and response, EMPERIE (www.emperie.eu/emp/), contract

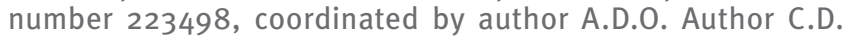
has received infrastructural support from the German Centre for Infection Research (DZIF) that included full funding of the position of author V.M.C.

Oligonucleotides can be ordered from stock at Tib-Molbiol, Berlin (www.tib-molbiol.de). Limited numbers of IFA slides as well as in-vitro transcribed control RNA for the $u p E$ and $1 A$ assays can be acquired from author $C$. D. through the European Virus Archive platform (www.european-virusarchive.com), funded by the European Commission under contract number 228292. Further information and assay updates can be obtained from www.virology-bonn.de. 


\section{References}

1. Zaki AM, van Boheemen S, Bestebroer TM, Osterhaus $A D$, Fouchier RA. Isolation of a novel coronavirus from a man with pneumonia in Saudi Arabia. N Engl J Med. 2012;367(19):1814-20.

2. Corman V, Eckerle I, Bleicker T, Zaki A, Landt O, EschbachBludau M, et al. Detection of a novel human coronavirus by real-time reverse-transcription polymerase chain reaction. Euro Surveill, 2012;17(39):pii=20285. Available from: http:// www.eurosurveillance.org/ViewArticle.aspx?Articleld $=20285$

3. Bermingham A, Chand M, Brown C, Aarons E, Tong C, Langrish $\mathrm{C}$ et al. Severe respiratory illness caused by a novel coronavirus, in a patient transferred to the United Kingdom from the Middle East, September 2012. Euro Surveill. 2012; 17(40): pii=20290. Available from: http://www. eurosurveillance.org/ViewArticle. aspx?Articleld=20290

4. ProMED mail. Novel coronavirus - Eastern Mediterranean: WHO, Jordan, confirmed, request for information. Archive Number: 20121130.1432498. Available from: http://www. promedmail.org/direct.php?id=20121130.1432498

5. ProMED mail. Novel coronavirus - Saudi Arabia (18): WHO, new cases, cluster, fatality. Archive Number: 20121123.1421664. Available from: http://www.promedmail.org/direct. php?id=20121123.1421664

6. Herzog P, Drosten C, Müller MA. Plaque assay for human coronavirus NL63 using human colon carcinoma cells. Virol J. 2008;5:138.

7. Rabenau HF, Cinatl J, Morgenstern B, Bauer G, Preiser W, Doerr HW. Stability and inactivation of SARS coronavirus. Med Microbiol Immunol. 2005; 194(1-2): 1-6.

8. Kraus AA, Priemer C, Heider H, Kruger DH, Ulrich R, et al. Inactivation of Hantaan virus-containing samples for subsequent investigations outside biosafety level 3 facilities. Intervirology. 2005; 48(4): 255-61.

9. Drosten C Chiu LL, Panning M, Leong HN, Preiser W, Tam JS et al. Evaluation of advanced reverse transcription-PCR assays and an alternative PCR target region for detection of severe acute respiratory syndrome-associated coronavirus. J Clin Microbiol. 2004;42(5): 2043-7.

10. Health Protection Agency (HPA). Genetic sequence information for scientists about the novel coronavirus 2012. London: HPA; 2012. [Accessed 4 Nov 2012]. Available from: http://www.hpa.org.uk/Topics/ InfectiousDiseases/InfectionsAZ/NovelCoronavirus2012/ respPartialgeneticsequenceofnovelcoronavirus/

11. Peiris IS, Chu CM, Cheng VC, Chan KS, Hung IF, Poon LL, et al. Clinical progression and viral load in a community outbreak of coronavirus-associated SARS pneumonia: a prospective study. Lancet. 2003; 361(9371): 1767-72.

12. Vijgen L, Moës E, Keyaerts E, Li S, Van Ranst M, et al. A pancoronavirus RT-PCR assay for detection of all known coronaviruses. Methods Mol Biol. 2008; 454: 3-12.

13. Peiris JS, Yuen KY, Osterhaus AD, Stöhr K, et al. The severe acute respiratory syndrome. N Engl J Med. 2003; 349(25): 2431-41.

14. He Q, Chong KH, Chng HH, Leung B, Ling AE, Wei T, et al. Development of a Western blot assay for detection of antibodies against coronavirus causing severe acute respiratory syndrome. Clin Diagn Lab Immunol. 2004; 11(2): 417-22.

15. Tan YJ, Goh PY, Fielding BC, Shen S, Chou CF, Fu JL, et al. Profiles of antibody responses against severe acute respiratory syndrome coronavirus recombinant proteins and their potential use as diagnostic markers. Clin Diagn Lab Immunol. 2004; 11(2): 362-71. 